\title{
O PROF. DR. EURÍPEDES SIMÕES DE PAULA, O CENTRO DE APOIO À PESQUISA EM HISTÓRIA - CAPH E A MEMÓRIA DA FFCL-FFLCH/USP: TRAJETÓRIA E POSSIBILIDADES
}

Elisabeth Conceta Mirra

Historiógrafa, CAPH-USP

\begin{abstract}
Resumo
Para homenagear o professor e doutor Eurípedes Simões de Paula, o Cento de Apoio à Pesquisa em História (CAPH), um de seus ideais concretizado, realizou uma sessão solene no dia 21 de novembro de 2007, recriou em suas dependências dois ambientes com objetos e documentos doados pela família do professor e apresentou o inventário de seu arquivo pessoal. Complementando esta homenagem, historiamos o CAPH dentro do contexto em que foi idealizado - guardião da "memória nacional" - até a atualidade, quando se transformou no guardião da "memória institucional" da Faculdade de Filosofia, Ciências e Letras (FFCL) e da Faculdade de Filosofia, Letras e Ciências Humanas (FLCH) da Universidade de São Paulo, ao custodiar sua produção científica (teses e monografias) e os arquivos pessoais de alguns dos docentes desta Instituição, como o arquivo do homenageado
\end{abstract}

\section{Pallavras-Chaves}

Inventário • memória institucional • memória nacional Faculdade de Filosofia, Ciências e Letras (FFCL) e da Faculdade de Filosofia, Letras e Ciências Humanas (FLCH) da Universidade de São Paulo.

\section{Abstract}

The Centro de Apoio à Pesquisa em História (CAPH), brainchild of professor EurípedesSimões de Paula, made a special session on November 21st 2007 to honour its creator and recreated (inside its own building) two spaces with objects and documents donated by professor de Paula's family. The centre also displayed an inventory of his personal archive. With the intention to complement this honour, we have also historicised the CAPH within its original context - as guardian of "national memory" - until the present day when it was transformed into the guardian of "institutional memory" for the Faculdade de Filosofia, Ciências e Letras (FFCL) and the Faculdade de Filosofia, Letras e Ciências Humanas (FLCH) of the Universidade de São Paulo. We have achieved this by maintaining holdings of its scientific production (dissertations and theses) as well as the personal archives of other professors who have worked in the same institution, in the same way as Euripedes' archive.

\section{Keywords}

Inventory • institutional memory • national memory Faculdade de Filosofia, Ciências e Letras (FFCL) e da Faculdade de Filosofia, Letras e Ciências Humanas (FLCH) da Universidade de São Paulo. 
Por ocasião da recordação dos trinta anos do falecimento do prof. dr. Eurípedes Simões de Paula, o CAPH, um dos seus ideais, através de suas diretoras profas. dras. Ana Maria de Almeida Camargo e Sylvia Bassetto, não poderia deixar de prestar sua homenagem àquele que o criou e que durante toda a sua vida acadêmica, com seu espírito pioneiro e empreendedor, contribuiu para o desenvolvimento científico e intelectual da FFCL-FFLCH/USP. Uma sessão solene realizada no dia 21.11.2007, no anfiteatro do Departamento de História, com a presença de autoridades, familiares, ex-colegas do departamento, representantes de institutos por ele criados e funcionários, registrou depoimentos emocionados de seus amigos. Ainda como parte destas homenagens foi recriado, no CAPH, dois ambientes (sala de jantar e escritório) da casa do prof. Eurípedes, para expor parte dos objetos e documentos doados a esta instituição. O objetivo desta mostra é de cunho didático, tentando colocar o visitante e/ou pesquisador em contato direto com o acervo textual utilizado e produzido por ele, como com o acervo tridimensional, fruto das relações de amizade profissional e familiar. ${ }^{1}$ Por outro lado, para complementar esta homenagem, gostaríamos de historiar o Centro de Documentação Histórica - $\mathrm{CDH}$ da Fapesp, o Setor de Documentação SD - do Departamento de História, e por fim o CAPH dentro do contexto em que foi idealizado - guardião da "memória nacional”, até a atualidade, quando se transformou no guardião da "memória institucional da FFCL-FFLCH/USP", ao custodiar a produção científica (teses e monografias) e os arquivos pessoais de alguns dos docentes desta instituição, como o arquivo do prof. Eurípedes Simões de Paula.

\section{Centro de documentação - guardic̃o da "memória nacional"}

Os registros das atividades humanas, sob vários suportes, autenticando o desenvolvimento histórico do seu povo, cabem às repartições culturais - sob a orientação dos arquivos nacionais; os arquivos públicos e particulares se responsabilizam pela tarefa de preservar, reunir e catalogar os documentos de interesse geral para estudos históricos e para o planejamento de futuras pesquisas científicas. Para que cumpram a sua tarefa social, administrativa, jurídica, técnica, científica, cultural, artística e/ou histórica, é necessário que estejam preservados, organizados e acessíveis. Estas tarefas são desempenhadas

${ }^{1}$ GONÇALVES FILHO, Manoel. Mostra recria universo do autor de Casa Grande \& Senzala. Jornal O Estado de S. Paulo, São Paulo, 26/11/2007. Caderno 2, p. 10. 
por quatro entidades - arquivos, bibliotecas, museus e, mais recentemente, os centros de documentação. ${ }^{2}$ Ainda que desempenhem a mesma função, elas diferem quanto ao tipo de documentos que guardam e quanto aos procedimentos técnicos usados para organizar e descrever seus acervos. ${ }^{3}$

No Brasil, entretanto, isso ainda não se realiza satisfatoriamente, devido, em parte, à falta de autonomia dos institutos existentes, privados que estão de verba orçamentária suficiente para por em prática os seus objetivos. Concorrem também para os resultados não satisfatórios, a ausência, até pouco tempo, de uma legislação que regulamentasse o arquivamento de seus acervos de modo metódico, bem como a falta de pessoal capacitado para executar as tarefas. Para se ter uma ideia desse quadro, o Sistema Nacional de Arquivos - Sinar, data de 1978; a regulamentação do profissional de arquivo, de 1978; o Sistema de Arquivo do Estado de São Paulo - Saesp, de 1984; a Política Nacional de Arquivos Públicos e Privados, de 1991 e a regulamentação da avaliação e eliminação de documentos públicos, de 1997, são alguns exemplos. ${ }^{4}$ Por sua vez, os cursos universitários pouco incentivavam as pesquisas. Para culminar essas dificuldades, constata-se que há uma quantidade enorme de documentos esparsos pelo vasto território nacional em condições precárias e de embaraçoso acesso. Desse modo, o trabalho é de tal monta que, o muito já feito em vários anos, resulta insignificante, levando a crer que a pesquisa pública brasileira esteja quase abandonada. ${ }^{5}$

Diante dos fatos assim descritos, não desanimou o Arquivo Nacional. Seus diretores transformaram esta entidade oficial em orientadora e indicadora de normas aos demais arquivos brasileiros. Convites às autoridades mundiais em assuntos arquivísticos, como T. R. Schellenberg, que, em visita ao Brasil, constatou que essa tarefa governamental é desprezada porque raramente os poderes públicos reconhecem valores em seus documentos até atingir a maturidade histórica, quando ironicamente, muitas provas relativas ao seu desenvolvimento,

\footnotetext{
${ }^{2}$ BELLOTTO, Heloísa Liberalli. Arquivos permanentes: tratamento documental. $2^{\mathrm{a}}$ ed. rev. e ampl. Rio de Janeiro: Ed. FGV, 2004, p. 14.

${ }^{3}$ TESSITORE, Viviane. Como implantar centros de documentação. São Paulo: Arquivo do Estado, Imprensa Oficial do Estado de São Paulo, 2003, (Projeto Como Fazer, 9), p. 11.

${ }^{4}$ BERNARDES, Ieda Pimenta. Como avaliar documentos de arquivo. São Paulo: Arquivo do Estado, 1998, (Projeto Como Fazer, 1), p. 66-70; 76-80; 85-87.

${ }^{5}$ IGLÉSIAS, Francisco. A pesquisa histórica no Brasil. In: XXIII Reunião anual da SBPC, Curitiba, 05/07/1971. Revista de História. São Paulo, v. 43, n. 88, out.-dez. 1971, p. 387.
} 
bem provável, já tenham desaparecido. ${ }^{6}$ Outras iniciativas desta instituição foram: publicação de traduções de obras especializadas em arquivística, organização de inventários, realização de cursos de formação e aperfeiçoamento de pessoal para arquivos. Quanto à proposta de inventariar os documentos, o Arquivo Nacional, como órgão técnico a serviço da historiografia nacional, o inventário deveria ser feito não só em sua instituição, mas também nos demais órgãos públicos, sobre os mais variados assuntos, para facilitar o trabalho de pesquisa. Conhecedor das dificuldades enfrentadas pelos pesquisadores para a elaboração de seus trabalhos, o prof. dr. Eurípedes Simões de Paula corroborou esta proposta e na sua Revista de História, um dos seus ideais, abriu uma seção Arquivos, para publicação das fontes primárias da história de São Paulo. Assim, a partir do $\mathrm{n}^{\circ} 8$ da revista, em 1951, passaram a ser divulgados arrolamentos de fontes históricas existentes nos arquivos municipais, estaduais, cartórios e demais instituições públicas de diversas cidades paulistas. Outros estados da União, além de instituições internacionais, passaram a colaborar enviando notícias sobre seus fundos de arquivo que interessavam para a História do Brasil.

Aos poucos, pesquisadores brasileiros como Francisco Iglesias, Américo Jacobina Lacombe e José Honório Rodrigues também não descuidaram de alertar sobre a importância da documentação histórica através de comunicações em simpósios e congressos, em obras sobre a evolução da pesquisa pública histórica brasileira. ${ }^{7}$

Todos esses trabalhos, iniciados há longo tempo, deverão ser continuados e intensificados, porque a tarefa é imensa. Assim, o Brasil tem a obrigação de lançar-se em uma cruzada de defesa do que ainda lhe resta do seu passado, de proteção das fontes de sua vida nacional, para não se transformar, em breve, em uma nação sem o álbum de retratos de sua infância e de sua adolescência. ${ }^{8}$

Felizmente, no momento de sua maturidade, diante do número crescente de pesquisadores estrangeiros que procuravam documentação inédita nos arquivos brasileiros para elaborar seus trabalhos acadêmicos, o problema documental

\footnotetext{
${ }^{6}$ SCHELLENBERG, T. R. Problemas arquivísticos do governo brasileiro. Rio de Janeiro: Arquivo Nacional, 1960, (publicação, 10), p. 10.

${ }^{7}$ RODRIGUES, José Honório. A pesquisa histórica no Brasil. $2^{\mathrm{a}}$ ed. São Paulo: Editora Nacional, 1969. (Brasiliana, v. 20), p. 37-118.

LACOMBE, Américo Jacobina. Introdução ao estudo da História do Brasil. São Paulo: Cia. Editora Nacional/Ed. da USP, 1973, (Coleção Brasiliana, 349), p. 122-144.

${ }^{8}$ OLIVEIRA, Franklin de. Morte da memória nacional. Rio de Janeiro: Civilização Brasileira, 1967, p. 43.
} 
tomou vulto e passou a chamar a atenção de autoridades e instituições de ensino e pesquisa.

Assim, cogitou-se a "implantação de centros de documentação, como uma etapa inevitável do progresso da comunicação científica”. A tendência adotada foi a especialização, dedicando-se cada novo centro a uma área específica de investigação. Surgem centros de documentação em universidades federais preocupados com a preservação dos documentos referentes à história regional como na UFPb, UFG, UFMT, entre outras. Com esse critério cuidadosamente planejado, o país teria, brevemente, inúmeros centros espalhados pelo seu território, em pontos estratégicos, capazes de servir com eficiência ao avanço da ciência. ${ }^{9}$ Ao lado destes centros de medicina, química, física, biologia, sociologia e outros, surgiram aqueles que seriam responsáveis pela preservação da cultura do país - os centros de documentação histórica.

A escassez de entidades desse gênero no país levou, mais uma vez, o espírito arrojado e inovador do prof. dr. Eurípedes Simões de Paula, com o auxílio inestimável de colegas como a profa. dra. Maria Regina da C. R. Simões de Paula e do prof. dr. Aziz Nacib Ab'Saber, além dos alunos do curso de PósGraduação em História, a idealizarem a criação, no Departamento de História da FFCL-USP, de um núcleo que pudesse pesquisar e proteger o restante do nosso passado histórico. ${ }^{10}$ A 15 de março de 1966 começou a funcionar o Centro de Documentação Histórica da Fapesp. Este órgão manteve o centro através de auxílios financeiros que permitiram a aquisição de equipamentos e materiais de consumo para a microfilmagem de fontes documentais até 1971, quando este foi definitivamente incorporado ao Departamento de História da FFLCH-USP, com o nome de Setor de Documentação. Neste período, o centro contou com a colaboração do prof. Frédéric Mauro que apresentou sugestões para ampliar e aperfeiçoar as áreas de atividades documentária e bibliográfica, bem como a reestruturação e elaboração do regulamento operacional do setor.

As metas primordiais do centro foram forjadas na orientação seguida pelo Instituto Anchietano de Pesquisas de Porto Alegre, através da Filmoteca His-

${ }^{9}$ HEGENBERG, Leônidas. Atualidade científica: documentação e pesquisa científica. Jornal $O$ Estado de S. Paulo, São Paulo, 04/08/1968, p. 46.

${ }^{10}$ RAMOS, Dulce Helena A. P.; GLEZER, Raquel. O Centro de Documentação Histórica da Fapesp. Separata da: Revista de História, São Paulo, v. 35, n. 72, out.-dez. 1967, p. 597-599. 
tórica do Padre Arnoldo Bruxel ${ }^{11}$ e pelo Institut de Recherches et Histoire de Textes, de Paris. ${ }^{12}$

As finalidades da instituição eram:

1 - Formar um núcleo informativo de documentação nacional e estrangeira para o estudo da história do Brasil, através do intercâmbio cultural entre os vários núcleos de pesquisa e preservação pela microfilmagem, de todo o acervo encontrado em condições precárias e de difícil acesso nos diversos estados da União;

2 - Reunir e catalogar documentos primários e bibliografias especializadas de interesse geral para estudos históricos e para o planejamento de pesquisas historiográficas;

3 - Oferecer aos pesquisadores e demais interessados os instrumentos de trabalho necessários para a reprodução de documentos encontrados, seja em São Paulo, ou em outros estados. ${ }^{13}$

Em 1984, o então Setor de Documentação passou a se chamar Centro de Apoio à Pesquisa em História - CAPH, denominação compatível com sua função, como centro de apoio à pesquisa institucional, acadêmica e individual. Em 1987, foi acrescido ao seu nome o do prof. Sérgio Buarque de Holanda.

Em 41 anos de existência, como centro de referenciação e informação, conseguiu reunir fundos documentais de vários tipos e naturezas e sob as mais diversas formas na área de ciências humanas e sociais (nacional e internacional), incluindo material audiovisual para subsidiar as atividades didáticas dos professores do Departamento de História. Todo este acervo vem recebendo tratamento documental adequado, são elaborados instrumentos de pesquisa catálogo - cujas informações estão contidas num banco de dados digital que tem demonstrado ser de grande valia para a pesquisa pública.

\footnotetext{
${ }^{11}$ RODRIGUES, José Honório, op. cit., p. 105-106.

${ }^{12}$ FRANÇA. Centre National de la Recherche Scientifique. Organisation et Statut des Personnels. Jornal Officiel de la République Française. Paris, n. 1.049, 1967.

${ }^{13}$ PAULA, Eurípedes Simões de. Relatório de atividades do Setor de Documentação do Departamento de História da FFLCH-USP. Revista de História. São Paulo, v. 24, n. 93, jan-maio 1973, p. 223-230.
} 


\section{Centro de Documentação - guardicão da memória institucional - FFCL/FFLCH-USP}

Os centros de documentação e memória nas universidades são voltados para a "geração de informações e para a organização de fontes de pesquisa". A partir de 1970, há um desenvolvimento destas instituições sobretudo nas áreas de ciências humanas e sociais, letras e artes, não só para atender à docência e à pesquisa, mas também, como a possibilidade de atuação profissional em vários campos de formação, devido ao trabalho interdisciplinar. Bons exemplos são: Cedic - PUC/SP, Cedem- Unesp/SP, Cedoc-UNB/DF, Unicamp, ProedesUFRJ, CDAPH-USF/Bragança Paulista-SP, entre outros. Assim, os centros de documentação passam a ter características próprias. Como entidade "mista", reúne documentos de arquivo, biblioteca e/ou museus, constituído de conjuntos orgânicos ou artificiais sobre determinado assunto, recebendo tratamento técnico arquivístico. ${ }^{14}$ Ainda, como "órgão colecionador e ou referenciador" tem por finalidade dar "informação cultural, científica, funcional, jurídica ou social especializada e apoio à pesquisa; seu objetivo é informar, mas pode ser também, instruir e provar”.

Na década de 1980, com a aproximação das comemorações do cinquentenário da USP e da FF (1934-1984), o CAPH iniciou uma nova tarefa: o projeto Memória da Faculdade de Filosofia da USP, visando recuperar a história desta instituição de ensino e pesquisa a partir da reunião de documentação textual, oral e iconográfica. A origem desta proposta remonta a 1982, com a criação do projeto Produção Científica e Historiográfica que objetivava centralizar no então Setor de Documentação do Departamento de História, artigos, resenhas, livros e outros trabalhos dos professores do Departamento.

A sugestão para ampliação dos objetivos do projeto partiu da direção da Faculdade de Filosofia, delegando ao Setor de Documentação a incumbência de recolher a produção acadêmica de toda a faculdade. Nova solicitação da diretoria da Faculdade indagava das condições para que o CAPH assumisse o papel de Centro de Documentação da Memória de cada departamento desta faculdade. Em resposta, o CAPH aceitou prestar mais este serviço à comunidade, apesar de suas limitações funcionais. Em publicação no D.O. de 07.02.1985 o CAPH foi reconhecido como "depositário de todas as dissertações e teses defendidas em âmbito desta faculdade”.

${ }^{14}$ TESSITORE, Viviane, op. cit., p. 13-14. 
A partir de 1986, o CAPH assumiu, diante do Departamento de História e da FFLCH, as funções de reunir, preservar e organizar a memória da FF, transformando-se, desta forma, no guardião da história da Instituição.

Coube inicialmente às historiógrafas do Setor de Pesquisa do CAPH elaborar a estrutura científica e técnica do projeto Memória, estabelecendo a metodologia adotada nesta segunda fase, na qual foram desenvolvidas as seguintes atividades: programação de depoimentos de representantes das diferentes seções da Faculdade de Filosofia (ciências exatas, naturais e humanas) e das diferentes gerações/turmas; levantamento de acervo bibliográfico de referência; consultas aos arquivos da instituição; divulgação de resultados através de circulares; levantamento dos currículos dos professores do Departamento de História; levantamento de roteiro para entrevistas e de critérios para a realização do trabalho arquivístico do material reunido.

A partir de 1991, o projeto Memória da FFLCH entrou na sua terceira fase, com o financiamento concedido pela Fapesp que possibilitou a contratação de seis pesquisadores, permitindo um trabalho mais sistemático e mais produtivo.

Em 25 anos de atividades, ora contando com o apoio da Fapesp (1991-1998), concedendo monitores-bolsistas e material permanente, ora da FFLCH-USP (2001-2006), o projeto conseguiu reunir 40 arquivos, constituídos por 31.877 documentos textuais, 6.132 documentos audiovisuais, além de 134 depoimentos e ou homenagens aos docentes da Faculdade de Filosofia da USP.

Para a organização dos acervos utilizou-se um tratamento arquivístico para os documentos institucionais e outro para os documentos pessoais.

Todo o material recebido está sendo processado tecnicamente - classificação, descrição, acondicionamento e conservação - de acordo com seus suportes. A disseminação da informação do acervo é feita através da elaboração de instrumento de pesquisa - inventário - e de sua inserção no banco de dados digital do CAPH.

A organização dos fundos doados ao CAPH, além de oferecer subsídios para a trajetória acadêmica de seus membros, possibilita a recuperação de parte significativa da história da USP, em particular da Faculdade de Filosofia, na área científica, tecnológica, pedagógica, burocrática e política.

\section{0 arquivo do prof. dr. Eurípedes Simões de Paula - Aesp (1910-1977)}

Os arquivos pessoais de cientistas, artistas e políticos constituem matéria privilegiada para que se possa compreender os processos de conhecimento, 
criação e decisão, razão por que, aliás, têm sido objeto de iniciativas de recolhimento por instituições diversas. Mas seria ilusório imaginar que tais processos se consubstanciam num ou noutro documento, ou que se explicitam de forma cabal. Demandam sempre o gesto de interpretação que, depois de cotejar evidências empíricas de diferentes matizes, cada qual atrelada a atividades específicas, logra lançar sobre elas um olhar mais distante, panorâmico, capaz de ultrapassá-las. Esse ato de ultrapassagem é prerrogativa do historiador. ${ }^{15}$

Em 06.08.1992, o CAPH recebeu, por doação de sua esposa, profa. dra. Maria Regina da Cunha Rodrigues Simões de Paula, o acervo do prof. Eurípedes, fundador deste centro e seu diretor até o falecimento em 1977. Um segundo lote foi efetuado em 28.09.2007, às vésperas da sessão solene em homenagem ao titular do arquivo.

O primeiro contato com a documentação foi feito pela historiógrafa do CAPH que realizou uma pré-organização do material recebido, elaborando o sistema de arranjo e o inventário sumário de acordo com as atividades profissionais do prof. Eurípedes, mantendo sempre que possível o respeito ao fundo, ou seja, a forma pela qual o titular organizou sua documentação. No período de 1997-2005, com várias interrupções, três equipes de bolsistas colaboraram no trabalho de arranjo, descrição, higienização, restauro e acondicionamento do acervo doado, sob a coordenação da historiógrafa da CAPH. Todo este trabalho está contido no inventário do arquivo do prof. dr. Eurípedes Simões de Paula, em quatro volumes, instrumento de pesquisa de grande importância para a consulta de seu acervo. Através do procedimento técnico-arquivístico utilizado na ordenação dos documentos é que se tentará esboçar o perfil do nosso homenageado.

Iniciamos nosso trabalho com a leitura da obra In memoriam de Eurípedes Simões de Paula que apresenta, além de artigos e biografia, um vasto número de depoimentos sobre a vida pessoal e profissional do titular que a todo o momento se mescla à história da Universidade de São Paulo e do Brasil. Consultamos, também, obras de referência sobre técnicas arquivísticas, participamos de seminários e visitamos instituições que realizam atividades afins.

\footnotetext{
${ }^{15}$ CAMARGO, Ana Maria de Almeida; GOULART, Silvana. Tempo e circunstância: a abordagem contextual dos arquivos pessoais. São Paulo: IFHC, 2007, p. 50.
} 
Após esses procedimentos, adotou-se um arranjo arquivístico que combinou séries funcionais, temáticas e/ou espécies de documentos. As séries foram divididas em subséries e dossiês, ordenados cronologicamente. Em alguns momentos deixou-se de lado a rigidez da classificação por suporte para integrar os documentos, sempre que se percebeu que isso ajudaria ao pesquisador na compreensão tanto do pensamento do prof. Eurípedes como das diversas atividades por ele desenvolvidas. Em seguida, elaboramos um inventário, instrumento de pesquisa capaz de atender as diversas classes de pesquisadores, "exaustivo" em seu conteúdo de informações e "seletivo" em seus métodos de análises de documentos, facilitando, dessa forma, o trabalho de conhecimento do arquivo consultado. ${ }^{16}$

Partindo do inventário sumário desenvolvemos o inventário analítico onde os documentos receberam tratamento individual para tornar mais conhecido o conteúdo e possibilitar a elaboração de outro instrumento de busca - os índices remissivos onomástico, temático e institucional - de grande valia para a consulta. Entretanto, quando se tratava de um documento do mesmo tipo, adotou-se uma descrição conjunta. A descrição dos verbetes foi feita em páginas ao invés de fichas por oferecer mais espaço para as informações e melhor visualização da organização do arranjo.

O Arquivo Eurípedes Simões de Paula - Aesp contém uma quantidade relevante de diversos tipos e suportes de documentos:

- textuais: 3.428 , perfazendo um total de 17.778 páginas;

- $\quad$ audiovisuais: 4.575;

- tridimensionais: 182.

Além disso, por abranger um extenso período, 1911 a 1994, caracteriza-se como um arquivo "por excelência". O procedimento técnico de arranjo possibilitou a organização de oito séries dispostas em maços e acondicionadas em 45 caixas-arquivo.

Das séries que compõem o Aesp fazem parte materiais produzidos, recebidos e coletados pelo titular no exercício de suas atividades discente, docente, administrativa, historiográfica e como integrante do Exército brasileiro, como

\footnotetext{
${ }^{16}$ SCHELLENBERG, T. R. Arquivos modernos: princípios e técnicas. Tradução de Nilza Teixeira
} Soares. $4^{\text {a }}$ ed. Rio de Janeiro: FGV, 2004, p. 315-316. 
também a documentação complementar reunida por sua esposa após o seu falecimento, que possibilitam a recuperação de parte significativa da história da USP, em particular da Faculdade de Filosofia.

Apresentamos em seguida uma descrição sucinta das Séries deste conjunto documental:

\section{Série I - Documentação pessoal}

Sequência de documentos composta de objetos pessoais, condecorações de guerra, móveis, lembranças da primeira infância, material escolar, instrução religiosa, homenagens, que registram sua vida escolar, acadêmica e militar.

\section{Série II - Documentação profissional}

Conjunto documental relativo à formação acadêmica (doutorado, cátedra), produção científica, documentos que comprovam suas várias atividades como:

- historiador: fomentando a criação de espaços para a produção intelectual como os centros de cultura e pesquisa, a gráfica da Faculdade de Filosofia da USP e a Revista de História;

- professor: de todas considerada a “atividade primeira”, constam documentos que mostram sua preocupação com a educação em todos os níveis (grau médio - luta contra a implantação dos Estudos Sociais, incentivo aos cursos de reciclagem de professores; grau superior - criação da Edusp, responsável pelo contato com editoras e livrarias nacionais e estrangeiras para aquisição de livros para a Biblioteca da recém criada FF-USP, além do seu precioso material didático constituído de fichas de aulas, fichamentos de livros, apontamentos, traduções, textos de cursos da então cadeira de História da Civilização Antiga e Medieval);

- administrador: documentação institucional, sobretudo correspondência administrativa reunida pelo titular quando diretor da Faculdade de Filosofia da USP (por cinco vezes), chefe do Departamento de História da Faculdade de Filosofia da USP (por três vezes) e diretor da Codac-USP;

- oficial da reserva do Exército brasileiro: constituído pelo dossiê assuntos militares elaborado pelo titular com documentos do CPOR (instruções, regulamentos, relatórios, apontamentos, trabalhos, certificado de curso) e o dossiê histórico-militar-febiano (1943-1945), além da correspondência 
enviada e recebida durante o período em que esteve em combate na Itália e o seu diário de campo das atividades do Pelotão de Morteiros do $1^{\circ}$ Batalhão de Petrechos Pesados sob seu comando, como $1^{\circ}$ tenente.

\section{Série III - Correspondência}

Cartas pessoais enviadas e recebidas, no período de 1927 a 1977, entre o titular, seus familiares, amigos e colegas da FF-USP e das universidades estrangeiras, destacando-se Jean Gagé e Fernand Braudel, professores da missão francesa, que organizaram os cursos de História da FFCL-USP. As cartas profissionais enviadas e recebidas foram arquivadas na série II, dentro da sub-série atividades do titular - como historiador, professor, administrador e oficial da reserva do Exército brasileiro - para complementar essas atividades e facilitar a consulta.

\section{Série IV - Documentos de terceiros}

Documentação avulsa de instituições públicas e particulares como boletins, manuais, mapas, folhetos, regulamentos e periódicos, além do dossiê Maria Garcia Simões.

\section{Série V - Periódicos}

Jornais de campanha e da grande imprensa nacional sobre a $2^{\text {a }}$ Guerra mundial: recortes com depoimentos e entrevistas do titular como educador e febiano, notícias de seus cursos e palestras em várias instituições de ensino.

\section{Série VI - Documentação complementar}

Documentação variada reunida de maneira artificial pela viúva do titular e organizada por assunto e/ou instituição, constituindo três sub-séries:

- homenagens póstumas, formada pelo dossiê In memoriam e pelas homenagens dos órgãos públicos;

- dossiê falecimento, com correspondência recebida de condolências, necrológicos, material fotográfico e publicações de terceiros sobre o titular;

- diversos, com documentos de terceiros (sobre o titular, Revista de História, FFCL-USP, FEB, Revolução de 1932 e USP). 


\section{Série VII - Material iconográfico}

Conjunto de documentos especiais constituído por:

- 1.726 fotografias (militares, familiares e acadêmicas);

- 2.819 slides (viagens culturais, familiares e $2^{\mathrm{a}}$ Guerra mundial);

- 1 filme (aniversário do titular);

- 1 microfilme (livro);

- 19 quadros (retratos, artísticos e formatura).

\section{Série VIII - Material fonográfico}

Conjunto de documentos especiais constituído por:

- 3 discos (posse do titular na FF-USP);

- 6 fitas magnéticas (aula magna e cursos).

Toda documentação que compõe o Aesp nos seus diversos suportes, audiovisual, textual e tridimensional, passou por um processo adequado de restauração e preservação até chegar à sua guarda definitiva.

\section{Considerações finais}

Ao relatarmos o histórico do Centro de Documentação Histórica, hoje CAPH, com seus quase 41 anos de existência, sob a ótica da pesquisa histórica no Brasil, visamos aliar-nos a todos os que, de uma maneira ou de outra, procuram levantar a consciência nacional para a importância da preservação de seu patrimônio documental nacional e institucional como elemento indispensável para que: os governantes possam consultar com facilidade sobre administrações anteriores; os pesquisadores de ciências humanas investiguem diretamente nas fontes; os historiadores, dispondo de suas ferramentas de trabalho, cumpram a sua missão, com exatidão e lisura; ${ }^{17}$ criação de novos centros de documentação histórica que venham a colaborar efetivamente nesta imensa e difícil tarefa de salvaguardar a memória de um povo e de suas instituições.

\footnotetext{
${ }^{17}$ VALETTE, Jean-Jacques. O papel dos arquivos na administração e na política de planificação nos países em desenvolvimento. Rio de Janeiro: Arquivo Nacional, 1973.
} 
Cabe salientar que os centros de documentação e memória nas universidades, diante da precariedade e/ou negligência da ação dos poderes públicos, responsáveis pela preservação, organização e disponibilização à consulta de seus acervos, tomaram a si esta tarefa com o intuito de trazer essas fontes documentais mais próximas do pesquisador.

Como outras instituições afins, o CAPH, no desejo de contribuir para a salvaguarda da memória nacional, passou a ter como área de especialização, a memória da Faculdade de Filosofia que reúne documentação institucional e pessoal sobre esta instituição de ensino, sob várias tipologias e suportes, dando tratamento arquivístico adequado, produzindo instrumentos de pesquisa, divulgando seu acervo e disponibilizando-o aos pesquisadores e subsidiando eventos e trabalhos como:

- exposições: Sessenta anos da Faculdade de Filosofia: ensino, pesquisa e participação social (1994); Memória da FFCL - FFLCH/USP, em comemoração dos seus 68 anos (2002); Setenta anos da USP e da FFLCH (2004) oferecendo subsídios para os vários institutos, unidades e seções que participaram das homenagens;

- $\quad$ artigos publicados e projetos desenvolvidos;

- $\quad$ subsídios a publicações e pesquisas acadêmicas nacionais e internacionais e aos sites da FFLCH e da USP.

Assim, como bem expõe Silvana Goulart, a valorização da memória interna da instituição reconstitui vivências pessoais e sociais que formam um quadro de analogias nas quais seus membros se reconhecem. ${ }^{18}$

Convém ressaltar ainda que a memória da Faculdade de Filosofia não se restringe ao arranjo arquivístico de conjuntos documentais individuais e institucionais. Como a memória individual, a da instituição está sempre em perene reestruturação a partir de questões propostas pelo presente. $\mathrm{O}$ trabalho que vem sendo realizado deverá acompanhar a vida da $\mathrm{FFLCH}$, fornecendo subsídios para

${ }^{18}$ GOULART, Silvana. Patrimônio documental e história institucional. São Paulo: Associação de Arquivistas de São Paulo, 2002, p. 36. (Scripta, textos de interesse para os profissionais de arquivo e áreas afins, 3). 
as suas transformações através da organização de vestígios e indícios escritos, orais, filmados ou fotografados de seu desenvolvimento. ${ }^{19}$

Apesar do CAPH ser reconhecido como centro de memória da FFLCH, ainda não há uma política institucional de remessa de seus documentos históricos e de transferência das doações das coleções particulares dos professores. Entretanto, estas dificuldades não impedem o projeto de construir, em largas pinceladas, os caminhos percorridos pela instituição. Tanto a documentação institucional, quanto os arquivos dos professores fornecem aos pesquisadores informações sobre sua formação, escolaridade, programas de curso, pesquisas desenvolvidas, além de atuação em diferentes áreas científicas ou administrativas. Existem muitas surpresas na consulta dessa documentação. Uma das verificações importantes é de que temas e métodos que são desenvolvidos hoje, como sendo das últimas décadas, já eram tratados nas décadas de 1930 e $1940 .^{20}$

Além disso, o CAPH apresenta-se como uma possibilidade real de local de estágio e treinamento de alunos do curso de História, na medida em que lhes oferece oportunidade de desenvolver uma atividade prática de organização de acervos, além de proporcionar o conhecimento e a reconstrução da história da Faculdade de Filosofia da Universidade de São Paulo. ${ }^{21}$

Os trabalhos técnicos de arranjo e descrição do Aesp e sua utilização em várias ocasiões nos permitiram tecer algumas considerações sobre as várias facetas do titular: historiador, professor, administrador, oficial do exército brasileiro e o cidadão Eurípedes Simões de Paula.

Tanto a produção acadêmica do titular, quanto o material por ele acumulado revelam sua contribuição para o aperfeiçoamento e difusão da educação nos seus vários níveis (primário, secundário, normal e superior). Provas incontestáveis disso estão na criação da Revista de História, de cursos de Hebraico, Estudos Orientais e centros como o Brasileiro de Estudos Judaicos, todos na USP; fundação de associações, centros de pesquisa e documentação (Sociedade de

\footnotetext{
${ }^{19}$ FACULDADE DE FILOSOFIA, LETRAS E CIÊNCIAS HUMANAS DA USP. Departamento de História. Boletim Informativo do Projeto Memória FFLCH-USP. São Paulo, n. 2, 1992, p. 9. ${ }^{20}$ FACULDADE DE FILOSOFIA, LETRAS E CIÊNCIAS HUMANAS DA USP. Departamento de História. Boletim Informativo do CAPH. São Paulo, n. 9, 1993.

${ }^{21}$ SILVA, Zélia Lopes da (org.). Arquivos, patrimônio e memória: trajetórias e perspectivas. São Paulo: Ed. Unesp/Fapesp, 1999, p. 154 ( Seminários \& Debates).
} 
Estudos Históricos, Instituto de Estudos Portugueses, Anpuh, CDH, entre outros); fomento e divulgação científica (Edusp, gráfica da FF-USP) e promoção de encontros, simpósios e congressos.

Com relação às ideias do titular desde seu tempo de estudante até a sua atividade como diretor, é através de sua correspondência pessoal e profissional que melhor podemos compreendê-las. Nela encontramos os primórdios da montagem dos cursos de História das Civilizações Antiga e Medieval, Moderna e Contemporânea, através da troca de sugestões entre o titular, Fernand Braudel e Jean Gagé. ${ }^{22}$ Nesta trajetória pessoal e profissional, por meio desta documentação, podemos "rever e analisar a memória da historiografia brasileira e da história em geral, na forma como nós a incorporamos" e "a importância das relações pessoais na constituição do seu projeto". ${ }^{23}$ A correspondência entre "os colegas Branca Caldeira e João Cruz Costa é significativa das relações das condições da pesquisa e do ensino da História na França e no Brasil". Ela "acompanha as vicissitudes da FF em seus primeiros tempos, a insegurança de seus alunos com relação ao mercado de trabalho, a carga docente e o ritmo de atividade necessário para responder as cobranças intelectuais e administrativas dos formandos numa Faculdade nova". ${ }^{24}$ As cartas e os cartões postais trocados entre 0 titular febiano e seus familiares e amigos retratam o militar enviando sinais de vida, aguardando ansioso resposta, não querendo ser esquecido, querendo estar presente no meio dos que o conhecem, trocando gestos de afeto e esperança de breve retorno. A censura é sentida nestes documentos através de recortes em partes das cartas onde constavam, talvez, notícias consideradas secretas e/ ou expressões impróprias para aquele momento de guerra. Juntamente com os jornais de campanha que reproduzem as verdades dos acontecimentos, dando notícias do desenrolar das operações, estes materiais integram dois mundos transformados pela guerra.

No conjunto documental iconográfico sobressaem: as fotos acadêmicas, familiares, militares e seus slides didáticos que são um retrato fiel do professor dedicado, amigo sempre presente e cidadão-patriota. No fonográfico, os

\footnotetext{
${ }^{22}$ BRAUDEL, Fernand. Paris, 4/02/1937; GAGÉ, Jean. Strasbourg, 19/01/1938 e 15/02/1939.

${ }^{23}$ THEODORO, Janice. Introdução. In: Revista Tempo Brasileiro. Rio de Janeiro: Tempo Brasileiro, ed., $\mathrm{n}^{\circ}$ 135, out-dez., 1998, p. 8 e 10.

${ }^{24}$ LEITE, Miriam Lifchitz Moreira. Projeto Memórias Educacionais: Sub-grupo Eurípedes Simões de Paula. (Relatório de Atividades à Fapesp). São Paulo, 1998.
} 
registros em discos e fitas magnéticas apresentam algumas de suas atividades administrativa e docente.

$\mathrm{Na}$ documentação complementar reunida pela esposa do titular, professora Maria Regina, destacamos, entre as homenagens póstumas, o dossiê In memoriam, que reuniu materiais variados - textuais, gráficos e fotográficos - para compor a obra In memoriam de Eurípedes Simões de Paula. Nela, além de estudos especialmente escritos, sua vida e obra, são registrados os depoimentos de amigos, colegas, alunos, intelectuais nacionais e estrangeiros, funcionários da FF-USP e pracinhas, seus ex-companheiros da FEB, que manifestam o carinho, a admiração e o apreço ao eminente homem, professor, administrador e febiano, Eurípedes Simões de Paula. ${ }^{25}$

Através de algumas citações constantes na parte referente aos depoimentos, tencionamos apresentar um perfil, àqueles que conviveram com ele e aos que não o conheceram, quem foi Eurípedes Simões de Paula.

Tive o prazer e o privilégio de conhecer Eurípedes Simôes de Paula. Um homem universal e ecumênico, amado e respeitado por pessoas de todas as raças, status e credos. Eurípedes veio ao mundo para cumprir a nobre missão de promover grandes ideais que unem todos os seres humanos: a liberdade, a justiça, o amor. E ele desempenhou a tarefa com dignidade, dedicação e coragem (Rabino Henry Sobel, p. 569).

Manteve a duras penas a "sua” Revista de História, abrindo tanto a colaboração dos historiadores já renomados na Faculdade de Filosofia, Ciências e Letras, como de estrangeiros, antigos mestres e de especialistas de áreas afins. Ainda de alunos, futuros historiadores, nos quais confiava e estimulava como poucos outros (Paulo Sawaya, prof. emérito de Zoologia da USP, p. 540).

O professor Eurípedes Simões de Paula foi, pelo que sabemos, o primeiro historiador brasileiro a tomar consciência da importância da história dos mundos não-europeus e a trabalhar para garantir um lugar para essa

\footnotetext{
${ }^{25}$ In memoriam de Eurípedes Simões de Paula: artigos, depoimentos de colegas, alunos, funcionários e ex-companheiros da FEB; vida e obra. São Paulo: Gráfica da FFLCH/USP, 1983, p. 9.
} 
história na universidade brasileira (Ricardo Mário Gonçalves, prof. de História da USP, p. 420).

O prof. Eurípedes foi um apaixonado pelas causas do ensino e dos professores. As campanhas que liderou contra os Estudos Sociais a favor da realização de concursos para o magistério viriam dignificar indelevelmente seus últimos anos (José Bueno Conti, prof. de Geografia da USP, p. 397).

Mais do que tudo, destacavam-se em seus atos o calor humano e a bondade, mercê dos quais as pessoas se sentiam cativadas e, muitas vezes, principalmente as mais humildes, amparadas (Paschoal E. A. Senise, prof. de Química da USP, p. 553).

Foi o prof. Eurípedes, na realidade, mais que um superior hierárquico, o grande amigo e conselheiro de todos aqueles que o procuravam. Sua virtude maior talvez tenha sido, para nós funcionários, a de saber nos ouvir com humildade e a de nos aconselhar e amparar com grandeza. Raro e talvez inexistente aquele que, ao sair de seu gabinete, não se sentisse amparado e fortalecido, pronto para enfrentar e vencer os obstáculos da vida (José Aldo Pasquarelli, funcionário da FFLCH-USP, p. 486).

Naquele dia de março observei pela primeira vez a sua pasta de trabalho sobre a imponente mesa. Que contraste! A valise era comum e desgastada pelo uso, não parecendo pertencer a um detentor de Croix de Guerre avec Palme. Futuramente eu iria entender que o conteúdo da pasta é que estava de acordo com o homem: instrumento de sua luta em favor das ciências e dos seres humanos, que a ele se vinculavam. Continha pesquisas importantes, trabalhos de alunos e documentos decisivos para o futuro profissional de grande número de pessoas (Kátia Maria Furtado de Mendonça Curtis, aluna de pós-graduação de História da USP, p. 402).

... De fato, feito expedicionário e combatente na Itália, Eurípedes tornouse "o nosso homem na FEB" e tínhamos orgulho disso. Granjeou grande reputação e o seu retrato, fardado, constou de mais de um quadro de formatura. De fato, combatendo de armas nas mãos o totalitarismo fascista, Eurípedes passou a encarnar o personagem, quase utópico, que não hesitara em abandonar o recesso de seus gabinetes de trabalho para defender, na prática, as suas convicções libertárias e aquilo que considerava 
o patrimônio cultural da humanidade, no momento seriamente ameaçado (Erasmo Garcia Mendes, prof. de Biociências da USP, p. 445).

Trinta anos são passados e na sessão solene em sua homenagem observamos a mesma emoção, o mesmo carinho daqueles que ao fazerem os seus depoimentos sabiam que ali estavam porque puderam contar com a mão amiga e confiante do professor, do administrador, do amigo e do cidadão Eurípedes Simões de Paula.

Como paraninfo da turma de 1951 da FFCL-USP, dirigindo-se aos licenciados oriundos de onze cursos diferentes, ao narrar as lutas e vitórias para que a FF se firmasse como instituição de ensino, concita-os a não desanimarem diante das dificuldades que certamente enfrentarão no exercício de sua tarefa primordial, qual seja, professores de ensino secundário, dizendo : “Ao contrário: aprestai as armas e lançai-vos à luta, para a conquista das cadeiras do ensino secundário, para a pesquisa pura nos laboratórios, nas bibliotecas e nos arquivos. Ajudai-nos a acabar com o conceito de que o licenciado é um universitário de 'segunda classe', ajudai-nos a combater pela equiparação total do título de licenciado ao das demais profissões liberais. ${ }^{26}$

"Não me tenho em conta de historiador. Sou apenas um professor de História” (Eurípedes Simões de Paula).

Este foi seu ideal maior e pelo qual batalhou a vida toda.

${ }^{26}$ ANUÁRIO DA FACULDADE DE FILOSOFIA CIÊNCIAS E LETRAS (Universidade de São Paulo) 1951. São Paulo: Secção de Publicações, 1952, p. 50-56. 